\title{
Stakeholder Engagement and Performance of Community Based Conservation Projects: A Case of Laikipia Conservation Region Conservancies
}

\author{
Hussein N. Ndonye ${ }^{1} \quad$ Angeline Mulwa $^{2} \quad$ Dorothy Ndunge Kyalo ${ }^{3}$ \\ 1.PhD Candidate, School of Open, Distance and Learning, University of Nairobi, Kenya \\ 2.Senior Lecturer, School of Open, Distance and Learning, University of Nairobi, Kenya \\ 3.Dean, School of Open, Distance and Learning, University of Nairobi, Kenya
}

\begin{abstract}
This study examined the influence of stakeholder engagement on the performance of Community Based Conservation (CBC) projects in Kenya. Guided by theory of change, participatory development and stakeholder theories, the philosophical underpinning employed was pragmatism where cross sectional study design that adopted convergent mixed methods approach composed of quantitative and qualitative strands was utilized. Questionnaires, focused group discussions and document analysis were used to collect data from seven community conservancies dotting Laikipia Ecosystem. The quantitative strand was composed of a survey that targeted 911 conservancy members involved in alternative livelihood projects from whom a sample of 270 was selected. The qualitative strand was made of eight conservancy officials in the focused group discussion and 11 documents. Quantitative data were analyzed using both descriptive and inferential statistics to test the nature and strength of the relationship between the variables and to predict performance of CBC projects based on the stakeholder engagement. Qualitative data was analyzed using framework analysis anchored on aprioristic set of categories viewpoint based on the indicators of the variables under study in order to triangulate the quantitative results. The results showed that stakeholder engagement positively and significantly influenced the performance of $\mathrm{CBC}$ projects since $\mathrm{r}=.641, \mathrm{R}^{2}=.410, \mathrm{~F}(1,237)=164.169$ at $\mathrm{p}=.001<.05$. Moreover, Welch's t-test showed that the level stakeholder engagement in $\mathrm{CBC}$ project design differed in the sampled community conservancies as $\mathrm{F}=$ $17.491 \mathrm{df}(6,231), \mathrm{p}=.001), \mathrm{t}=19.944 \mathrm{df}(6,75.765)$ at $\mathrm{p}=.001<.05$. It is recommended that external expertise should only be used as a compliment to the local one, therefore, local stakeholders should be engaged for their customary and the traditional knowledge. Innovations and practices of local communities relevant for the conservation and sustainable use of biodiversity ought to be encouraged. Given the importance attached to local knowledge in $\mathrm{CBC}$ projects, there is need to have effective communication and outreach to and with local stakeholders, particularly the local cultural institutions who retain traditional ecological knowledge.
\end{abstract}

Keywords: Conservation, Development, Stakeholder Engagement, Community Empowerment, Acceptance of Conservation, Sustainable Resource Use, Biodiversity Regeneration

DOI: $10.7176 / \mathrm{JESD} / 12-4-07$

Publication date: February $28^{\text {th }} 2021$

\subsection{Introduction}

The old philosophy of conservation emphasized on insulating certain biodiversity zones from human contact. It was called fortress conservation, protected nature by exclusion and restriction of access, a measure that oftenrequired use of force on the local communities already accustomed utilization of the natural resources. According to Newmark and Hough (2000) fortress conservation was territorial in that, land was set aside, preserved in its natural condition and human activities limited to cases where a species was threatened or endangered. Fortress conservation alienated local communities denying them to resources they have always depended on and failed to halt the decline of biodiversity. Pursuant to this, conservation and participatory development practitioners mooted a new paradigm that acknowledged local communities, making the latter central to conservation and rural development. The centrality of local community as stakeholders in conservation was meant to bring back traditional ecological knowledge to natural resource management. Through stakeholder engagement, local and indigenous knowledge systems that always had strategies for human-nature coexistence inbuilt from ancient times could be adopted to curtain biodiversity loss.

\subsection{Statement of the Problem}

The efforts by conservation and participatory development practitioners culminated into Integrated Conservation and Development Projects (ICDPs). The ICDP approach was meant to address the often-conflicting goals of conservation and rural development. This paradoxical concept of balancing between conservation and development was three decades ago boosted by the publication of "Our Common Future" the Brundtland Commission Report in 1987 (WCED, 1987). Brundtland Commission Report attributed critical global environmental glitches to enormous poverty of the Southern Hemisphere and the non-sustainable consumption 
and production patterns in the Northern Hemisphere and ultimately recommended for a strategy to unite development and environmental preservation, the sustainable development. To spur sustainable development in biodiversity rich areas of Kenya, the CBC projects are the most preferred variant of ICDP. According to Vargas and David (2014), CBC projects are designed on the assumption that local communities are critical to the realization of development and conservation. It is anticipated that based on theory of change, the provision of benefits to the local community will result in support of conservation because it is economically beneficial. To achieve this, the engagement of local stakeholders is a central feature of CBC projects. However, there is a dearth of empirical evidence in conservation literature that shows the effect of local stakeholder engagement on the performance of $\mathrm{CBC}$ projects in the world.

\subsection{Test of Hypothesis}

The purpose of this study was to examine the influence of stakeholder engagement on the performance of CBC projects in Kenya with special focus to community conservancies in Laikipia Ecosystem. The study sought to test the following hypothesis:

$\boldsymbol{H}_{1}$ : There is a significant relationship between stakeholder engagement and performance of CBC projects in Laikipia region.

Further, management of natural resources is complex and engaging local stakeholders in that management exacerbates the complexity. To this end, based on the stratified sampling that assumed the heterogeneity and diversity of local stakeholders, the alternative livelihood projects members in the conservancies. The following hypothesis was tested to confirm this assumption.

$\boldsymbol{H}_{1}$ : Group means are different $(\mu A \neq \mu B)$

\subsection{Literature Review}

\subsection{Performance of CBC Projects}

In project management, different project managers have various definitions of performance depending on context, experience and knowledge. The UNDP (2009) defines performance of a project as the progress towards and achievement of intended results. Lester (2013) argues that the performance of a project is based on key performance indicators such as milestones to be met and especially the predetermined design, deliverables, and the planned production. There are suggestions that the performance should be studied from the perspective of project goals as well as the performance of the project processes. This study was about the influence of stakeholder engagement on the performance of $\mathrm{CBC}$ projects. $\mathrm{CBC}$ projects are in practice complex undertakings with multiple social, cultural, political and ecological factors that can be affected by project design aspects like stakeholder engagement. CBC projects are implemented in ecological communities comprising of complex networks of individuals that interact with each other and with the environment.

Complexity of issues change with geographic scope, types of stakeholders involved, differential interests and local contexts (Catacutan and Tanui, 2007). Project complexity negatively influences upon project management process and particularly on the project itself and therefore the performance of CBC projects is inched to how the complexity in them is addressed in the project design. The project design aspect of stakeholder engagement is an important factor of addressing such complexity in order to link conservation and local development. In addressing this linkage, the first step is the consideration of where the conservation and community needs intersect (Brown and Wyckoff-Baird, 1995). The intersection of conservation and community needs occurs at the optimum, a point where community interventions that result in conservation and wise use of the natural resources are possible. At the optimum, local stakeholders view the future of their livelihoods as a function of their present practices and use of resources, they are likely to adopt more sustainable methods. This is because in the end, the performance and sustainability of integrated conservation initiatives adopting CBC model depends on positive impacts to the local community (Suich, 2013). This is because there exists a connection between conservation and socio-economic well-being of local communities.

The performance of a CBC project is a multidimensional construct with human, economic and ecological dimensions. Dangi and Jamal (2016) agreed to this assertion, arguing that in an integrated approach to sustainable community-based tourism, project performance should be seen through the lens of economic sustainability, social sustainability and environmental sustainability. CBC projects provide an incentive for the sustainable management of biodiversity resources. This is because $\mathrm{CBC}$ projects link maintenance of ecosystems with poverty alleviation and livelihoods benefits for the local community. In recognition these multiple perspectives, according to Brooks, Waylen and Mulder (2012), the performance of CBC projects can be measured in four outcome domains of ecological, economic, attitudinal and behavioural outcomes. It was based on these concepts that in this study, CBC project performance was measured by economical outcomes (community empowerment), attitudinal outcomes (acceptance of wildlife conservation), behavioural outcomes (sustainable resource use) and ecological outcomes (biodiversity regeneration). 


\subsection{Stakeholder Engagement}

Stakeholder engagement is an important ingredient for successful project delivery. The core idea within project stakeholder engagement is that project managers can increase the likelihood of project success by influencing the project stakeholders (Eskerod and Larsen, 2018). CBC projects occur in complex environments with stakeholders of conflicting goals. To this end, it is critical to identify the stakeholders and further seek to understand their influence on a CBC project in order to balance their demands, needs, and expectations. Since conservation project managers lack the formal power of authority to make stakeholders to respond to project inputs and outputs, they therefore have to rely on stakeholder engagement to achieve project objectives. This study argues that the local community can be made to respond positively to a CBC project through stakeholder management. However, the truth is that project management in conservation exerts no formal power of authority over the various local community and therefore has to rely on engagement to achieve the planned objectives.

Engagement of stakeholders leads to empowerment and to joint-ownership of the project. Based on this premise, $\mathrm{CBC}$ project designers must focus on constant and continuous engagement and communication with the local community to understand their needs and expectations. Sterling, Betley, Sigouin, Gomez et al. (2017) admit that local community participation featured centrally in biodiversity conservation projects globally. On the indispensability of local stakeholders in achievement of project objectives, Bal, Bryde, Fearon and Ochieng (2013) opine that the latter often possess a wealth of information, they can promote project reputation, help build relationships and by far better understand local priorities and needs. The researcher used inclusion, the integration of local values in terms of traditional knowledge and the participation of locals in the management of resources as indications of stakeholder engagement that influence the performance of $\mathrm{CBC}$ projects.

\subsection{Stakeholder Engagement and Performance of CBC Projects}

Conservation projects do not exist in isolation, but within a local context populated by communities who have a particular interest in the project outcomes. Stakeholders are people, groups, or organizations that affect or are affected by a particular project (PMI, 2017). There exists a wide range of definitions and interpretations of stakeholder engagement. In an early text, Cohen and Uphoff (1977) defined stakeholder engagement as the promotion of the involvement of people in the planning and implementation of development efforts as well as in the sharing of their benefits. Understanding stakeholder dynamics is very important in project design, as engaging stakeholders is widely acknowledged to be an essential part of project management and a factor contributing to project success.

Engaging stakeholders allows project management to increase stakeholder support and minimize resistance and therefore significantly increasing the chances to achieve project success. A conservation project design that lacks of local stakeholder involvement leads to wavering support (Muhumuza and Balkwill, 2013). It is against that background that stakeholder engagement approaches are heralded as the panacea to conservation initiatives worldwide. Arguing from a normative point of view, Reeds (2008), pointed out that engaging stakeholders in environmental decision-making was increasingly getting recognized as a locals' democratic right. Engagement of the local community can even boost chances of project success without direct benefits. Moreover, Treves, Wallace and White (2009) pointed out that participation in decision-making raised tolerance for wildlife or management even in the absence of measurable reductions in threats. In addition to these normative arguments, many pragmatic benefits have been claimed for engagement; for instance, Reeds (2008) argues that engagement improved the quality and durability of environmental conservation decisions, but cautioned that claims of stakeholder engagement in environmental issues have rarely been tested. All in all, the complex and dynamic nature of conservation projects requires flexible and transparent decision-making that embraces a diversity of knowledges and values.

Interacting with local stakeholders of a project can be broken down several types of engagement. According to FAO (2003) there are three main modes of engagement in projects. Type I; the induced involvement whereby the design, strategy, and work plan of a project are usually determined in advance and the anticipated beneficiaries are encouraged to partake in its activities in order to attain certain benefits. In this type, people are requested to make contributions of labour or other resources, which is also seen as a form of cost sharing. Type II; transitory mobilization for development of a community where by the people partake in certain specific temporary tasks for the advancement of their community, however, there is no structure for continuous participation. Lastly, Type III; group formation, here, project's purpose is to help craft new or reinforce existing self-formed and self-run groups and organizations through which local community can access resources, inputs, services and actively participate in the initiative by means of self-proposed activities.

For CBC projects to perform in the complex environments, Type III is more appropriate since it espouses the type of engagement that leads to empowerment of the local people through the sustainable livelihood framework of building human, physical, social, financial and natural capacities where local stakeholder engagement take the centre stage. To this end, Hart, Burgess and Hart (2005) point out that there is a concurrence regarding the general principles of community involvement desirable for an initiative to be regarded 
participatory. Through existing self-formed and self-run groups, local communities achieve not only right to resources, but also negotiating power, decision-making and a base for continuous self-development efforts. Type III engagement provides a fertile ground for the linking of conservation and development which are priorities for the participating local community. Moreover, it can be highlighted that there is a broad range of engagement types that could be employed in the design of CBC projects for performance.

Based on the stakeholder theory, past research has identified several principles of stakeholder engagement that could act as an influence in the association between project design and CBC project performance. On this, Brooks et al. (2013) pointed to local participation as when the project materializes at the impetus of the community and the latter partakes in project formation and daily running. This comports Hart et al. (2005) local identification where by the idea of the required intervention comes from the local community. Local conceptualization in the notion that the local people participate in the setting of the intervention agenda and its facets based on recorded and analysed data (Hart et al., 2005). Arguing for bottom-up approach in CBC projects through devolution to achieve local control, Campbell and Vainio-Mattila (2003) cited Hackel (1999) who had suggested that decentralizing the management of a resource to local communities from central authority was the linchpin for a successful CBC project. Participation in design of a $\mathrm{CBC}$ project enhances local control as participants are engaged in the project and progressively take control of the process and the use of the project outcomes.

At this point, six stakeholder engagement principles have now clearly come out; shared ownership, local project identification, local conceptualization, local control, equity and empowerment. Linking conservation and local development can utilize these principles as they make the role of local community prime. This is because prioritization and local needs will be better addressed in such a project design environment. On this Eskerod et al. (2015, citing Freeman, 1984) lamented that understanding and integrating the needs and concerns of groups is the pathway that an organization can use to design its goals in a way that would make the groups to back the organization and thereby enhancing its chances for survival, which here means project performance.

\subsubsection{Inclusion of Local Stakeholders}

Due to complexity in conservation areas where CBC projects are implemented, the inclusion of local community as stakeholders ought to be part of project design from the earliest of stages. At this early design phase, there is scope to effectively influence options and implement the change required to respond to needs. Bouamrane, Spierenburg, Agrawal, Boureima et al. (2016) highlighted the importance of early stakeholder inclusion in conservation projects in order to build knowledge for achieving sustainable development. The review of lessons learned from biosphere reserves case studies found that complexity in conservation areas brought about by the diversity of stakeholders and their different needs and perceptions about nature conservation usually complicated implementation processes, resulting in conflicts about the project objectives in some instances. The authors (Bouamrane et al., 2016) posit that inclusion and dialogue among the different stakeholders must start early in the project design and planning phase and be based on the principle of social and ecological solidarity, and that the dialogue must then be pursued, formalized, ritualized, and translated to gain local community support. Inclusion of stakeholders through effective communication, decision making, collaboration is critical to the success of complex conservation projects.

However, it is imperative to note that local community inclusion in conservation project management is not an end by itself, engaging stakeholders by having their active voice in the $\mathrm{CBC}$ project design empowers them. By knowing that their views, voices and preferences are valued, a local community would regard the project as promoting their needs. Therefore, inclusion yields community empowerment and according to Hart et al. (2005) empowerment strengthens locals and their institutions by making them aware of their resources and abilities while supporting their mobilization and organization. This empowerment can be rooted in the recognition of the local community traditional ecological knowledge. Borrowing from participatory development praxis-theory debate, Campbell and Vainio-Mattila (2003) pointed out that in CBC projects, there could be no universal "metatruths" on conservation separate from, or implemented in separation from the context within which people interact with the ecosystems for which strategies of conservation are being designed. The argument on the context here elevates the centrality of local inclusion and the essence of traditional knowledge systems. CBC project designers are therefore called to moot strategies that empower traditional knowledge systems created through long, reciprocally adaptive processes of local people intermingling with their surroundings as they could boost effort of conservation.

\subsubsection{Integration of Local Values}

Integration of local values in terms of traditional ecological knowledge is a key strategy for CBC projects to win support, attain local commitment, and ultimately improve the chances for sustainability performance. CebrianPiqueras, Filyushkina, Johnson, Lo, et al. (2020) used snowball sampling method on a population stratified by age, gender and geographical distribution. The researchers employed a face-to face survey administered to residents next to a conservation area. Using multi-variate analysis that included partial least squares path modelling to test hypotheses, the results show that traditional ecological knowledge as a core principle in 
conservation project design improved ecosystem service provision, sustainability as well as resilience of socialecological systems. Although the, the inferential power of the methodology is meagre, the study sheds light on the fact that integration of local community traditional ecological knowledge transmitted through generations was important in conservation project design. Based on this knowledge, conservation initiatives and alternative livelihood projects promoting local development can be modelled.

The justification for integration of local values in the design of conservation initiatives does not invalidate the knowledge of conservationists. Expert knowledge is indispensable in conservation; however, projects cannot be planned exclusively based on expertise that emanates from studies conducted by experts from outside. This is justified by Ballet, Koffi and Komena (2009) in that, local institutions and the communities supporting outside experts play an essential role in the efficient and sustainable management of natural resources. Local people and other stakeholders may not have the required technical expertise and experience to undertake a particular project, therefore requiring input of experts from outside. By the same token, the experts and researchers from outside may not necessarily have a better understanding of local conservation issues than insiders and they, too, will need assistance from locals. In conclusion, there is importance of CBC project partnerships determining whether the conservation model employed was compatible with cultural worldviews regarding people-nature relationships and that $\mathrm{CBC}$ project goals and activities ought to integrate the values of the local stakeholders and not to infringe on local livelihood practices.

\subsubsection{Local Stakeholder Participation}

Stakeholder engagement and participation, whether in development, environmental conservation or in other spaces has several benefits. Michener (1998) classified participation based on these benefits into two approaches, the planner-centred benefits approach and people-centred approach. Planner-centred benefits approach is described as the approach geared towards administrative and financial efficiency whereas people-centred approach empowers locals by enhancing their management capacity, increasing confidence in native potential and improving shared consciousness, as well as realizing local priorities and needs. The main motivation of a planner-centred perspective is that the stakeholder participation in a CBC project design is that it brings commitment to the project success. Michener (1998); Bene and Neiland (2006) also rooted for local engagement by suggesting that native knowledge and local labour could be utilized and in-kind assistances to programs can lower implementation costs. For instance, early in the project design stages, indigenous institutions could be utilized in community mobilization and whipping. People-centred perspective is geared towards increasing participatory decision-making, self-reliance and social justice.

Furthermore, throughout the implementation of $\mathrm{CBC}$ projects, the local community ought to participate actively in the conservation and the development initiatives, more so by means of self-proposed actions. Based on this premise, securing active participation of project beneficiaries in early project design activities such as needs assessment to create impetus and participation in decision-making is indispensable. Participation in needs assessment in community projects is known to have significant and positive influence on the project sustainability. Aga Noorderhaven and Vallejo (2018) applied experimental design to probe active project beneficiaries' participation in needs assessment. The results show that project beneficiaries' participation in needs assessment and involvement in planning stages had a significant positive influence on the behavioural intentions of the project beneficiaries toward project sustainability. This is an evidence that participation of local community as project beneficiaries in decision-making produces sustainable and more effective projects.

Moreover, empowered local stakeholder is the key to higher project overall performance. Literature reviewed (Reeds, 2008; Bene and Neiland, 2006; Michener, 1998) suggested that genuine, people-centred, active or transformative participation often leads to empowerment, whilst planner-centred participation tends to be nominal with local people acting as the passive recipients of development. A CBC project design should target to be participatory for better performance and sustainability by enhancing the capacity of the local community and seeking synergy with indigenous systems. Participation of stakeholders in crucial in all types of projects. For instance, in construction project management, Heravi, Coffey and Trigunarsyah (2015) surveyed 200 construction companies to examine the level of stakeholder involvement during the project planning process. The results of the analysis demonstrate that it was prudent to engage stakeholder groups in the project planning process phase. The study further establishes a basis for further stakeholder involvement improvement to guarantee project success. Reeds (2008) claimed that stakeholder participation increases the likelihood that environmental decisions being perceived as holistic and fair. To this end, stakeholder participation will be able to boost positive attitudes towards conservation and lead communities to behavioural changes.

\subsection{Methodology}

3.1 Study Area

Laikipia region is found in Kenya's Great Rift Valley, tacked between Mount Kenya and the northern deserts, this savanna grassland ecosystem is rich in biodiversity. The area had been a patchwork of huge ranches, an important livestock district where one of Kenya's most encouraging conservation success stories are unfolding. 
According to Sundaresan and Riginos (2010) the region is a home of the highest diversity of large mammals than any other region in East Africa. Group ranches is a form of communal land ownership where by a group of households from the local community own and manage their land under the $\mathrm{CBC}$ approach. The conservancies in Kenya have become central in the evolution of new institutional arrangements for community involvement in conservation and tourism. Data for the study were collected from the community conservancies in the Laikipia ecosystem: Naibunga Upper, Naibunga Central, Naibunga Lower, Il Ngwesi and Lekurruki, Makurian and Kuri Kuri.

\subsection{Data Collection}

A cross sectional study design was adopted with data being collected from a predetermined population at just one point in time. The target population was geographically diverse and therefore, multistage sampling based on the hierarchical structure of the natural clusters within the population was adopted. First, the respondents were drawn from all the seven community conservancies identified to be constitutes in CBC models. Since the number of organizations under consideration was less than 200, a census of the organizations was preferable rather than a sample (Watson, 2001) and therefore respondents of this study were drawn from all the 53 community-based organizations (CBOs) identified in the in the seven conservancies. Lastly, due to the assumed heterogeneity of the target population based on the conservancies, the study adopted stratified random sampling to target the members CBOs in the respective. It was assumed the representation of the population under study increased the efficiency of the study.

The target respondents comprised 911 CBO members involved in Livestock Works, Bead Works, Tourism Works, Bee Keeping and Moran Enterprises. The sample size was determined based on the formula proposed by Krejcie and Morgan (1970), which gave a sample size sufficient to provide accuracy to infer the findings to the population with confidence. See equation (1).

\section{$S=X^{2} N P(1-P 0) /\left(d^{2}(\mathbf{N}-1)+X^{2} P(1-P)\right.$}

Where

$\mathbf{S}=$ required sample size;

$\mathbf{X}^{\mathbf{2}}=$ the table value of chi-square for 1 degree of freedom at the desired confidence level (3.841);

$\mathbf{N}=$ the population size (911);

$\mathbf{P}=$ the population proportion (assumed to be 0.50 since this would provide the maximum sample size);

$\mathbf{d}=$ the degree of accuracy expressed as a proportion $(0.05)$

Therefore: $\mathrm{S}=\mathbf{3 . 8 4 1}(\mathbf{9 1 1})(.50)(1-.50) / 0.052(911-1)+3.841(.50)(1-.50)=270.39$

Therefore, 270 respondents were selected for this study, out of which 238 responded. In the qualitative strand of the study, eight officials of the conservancies were purposively picked for the focussed group discussion and 11 conservancy documents comprising of annual conservancy reports, conservancy strategic plans, and progress reports were reviewed.

Convergent mixed method design was used in this study, specifically the parallel-databases variant (Creswell and Plano-Clark, 2011) where two parallel strands of quantitative and qualitative data collection were conducted independently and only brought together during the interpretation. Quantitative analysis comprised of descriptive statistics that included means, frequencies and standard deviations. Inferential statistics employed the use of Pearson's Product Moment of Correlation (r) to investigate and test the nature and strength of the relationship between variables and to predict the CBC project performance based on capacity building of project beneficiaries. Data from focussed group discussions and document reviews was sifted, charted and sorted in harmony with aprioristic set of categories viewpoint based on the indicators of the variables under study. Five steps were employed, that is; familiarization with the data, theme identification using indicators, indexing, charting, and mapping and then interpretation.

\subsection{Likert Scale as an Interval Measure}

In the quantitative strand of the study, a questionnaire with Likert Scale type questions was used. Based on Carifio and Perla (2008) it is perfectly appropriate to sum Likert items and analyse the summations parametrically, both univariately and multivariately. The Likert questions in this study were designed as a series of questions that when combined would measure a particular trait by calculating a composite mean from the Likert-type items. Jr and Boone (2012) advised that composite score for Likert scales should be analysed at the interval measurement scale. Pursuant to these arguments, this study therefore assumed parametric statistics were sufficiently robust to yield largely unbiased answers that are acceptably close to "the truth" on analysing Likert Scale responses from the questionnaire. Composite scores were used in analysis and decision rules after analysis of mean scores were guided by the logical equal levels of the score approximated to the first decimal point in line with equidistance arguments (Lantz, 2013). This study used one verbal anchor; $1=$ Not at all (NA); $2=$ To a little extent (LE); 3 = To a moderate extent (ME); $4=$ To a great extent (GE); $5=$ To a very great extent (VGE). The judgment rule in this study followed these arguments; Not at All for values lying between $1<\mathrm{NA}>1.8$; To a 
little extent for values between $1.8<\mathrm{LE}>2.6$; To a moderate extent for values between $2.6<\mathrm{ME}>3.4$; To a great extent for values between $3.4<\mathrm{GE}>4.2$; To a very great extent for values between $4.2<\mathrm{VGE}>5.0$. This creates a scale that has an equidistance of 0.8. Correlations coefficient was used to measure relationships. Decision rule followed Cohen (1988) suggested guidelines that r-value of between .10 to .29 means small or weak correlation; r-value of between .30 to .4 .9 means medium or moderate correlation and r-value of between .50 to 1.0 means large or strong correlation.

\subsection{Results and Discussion}

\subsection{Descriptive Analysis of Stakeholder Engagement}

Engaging local stakeholders is a fundamental feature of CBC projects globally and presents prospects of the local community to partake in consultations and decision-making, reduce probable conflict, and achieve sustainability. The sustainability in CBC projects could be realized through stakeholder engagement as it shifts individual attitudes and behaviors to favorably promote conservation and local development, ultimately achieving empowerment of local communities, acceptance of wildlife conservation, enhance sustainable resource use and biodiversity regeneration. The descriptive analysis of the composite score scores of stakeholder engagement in $\mathrm{CBC}$ projects are shown in Table 1.

Table 1: Descriptive Analysis of Stakeholder Engagement

\begin{tabular}{lccccc}
\hline Indicator & $\mathbf{n}$ & Min & Max & $\boldsymbol{\mu}$ & $\boldsymbol{\sigma}$ \\
\hline Inclusion of Local Stakeholders & 238 & 2.00 & 4.80 & 3.5824 & .49284 \\
Local Values Integration & 238 & 2.50 & 4.75 & 3.7668 & .52894 \\
Local Stakeholder Participation & 238 & 2.00 & 4.50 & 3.5049 & .47915 \\
\hline Composite Mean & $\mathbf{2 3 8}$ & $\mathbf{2 . 2 0}$ & $\mathbf{4 . 5 3}$ & $\mathbf{3 . 6 0 0 6}$ & $\mathbf{. 4 0 7 8 5}$ \\
\hline
\end{tabular}

$\mathrm{n}=$ Sample Size; $\boldsymbol{\mu}=$ Mean; $\boldsymbol{\sigma}=$ Standard Deviation

The research findings in Table 1 indicate that indicators of stakeholder engagement in CBC projects, had means ranging from 3.5049 to 3.7668, showing they were factored to the $\mathrm{CBC}$ projects to a great extent. Local values integration had the highest composite mean $\mu=3.7668$ with standard deviation $\sigma=0.52894$. This signals that to a great extent; $\mathrm{CBC}$ project designers were cognizant that local values could build the local support and interest and its indispensability in sustainable development. The inclusion of local stakeholders in CBC projects in all project's phases came in second and was to a great extent $(\mu=3.5824$ and $\sigma=0.49284)$. This indicates the importance that $\mathrm{CBC}$ project designers vested on strengthening local stakeholders' abilities by incorporating local knowledge and opinions in the planning and management of conservation and development projects. Public participation in CBC project design ranked third, with mean $\mu=3.5049$ and standard deviation $\sigma=0.47915$, showing it was to a great extent. This indicates that the project designers were geared towards generating a shared commitment to sustained and continuous stakeholder engagement that responded to needs of communities and target groups. Successful stakeholder engagement could help build relationships and trust necessary the sustainability of conservation projects and impactful change. Overall, the composite mean $\mu=3.6006$ and standard deviation $\sigma=0.40785$ indicate that local stakeholder engagement was mainstreamed to the CBC project design to a great extent.

From the qualitative stand, the respondents in the focused group discussion indicated that the design of the $\mathrm{CBC}$ projects recognized the community as supreme in project decision making, project identification and running of the projects in the conservancies. It was evident that the projects were in preference of inclusivity and people-centered approach to planner-centered one. This was affirmed by arguments that the community was at the top of conservancy organization structure, the youth and women were part and parcel of the decision-making process and that the resources in the conservancy belonged to the local community. The focused group discussions bore sentiments like;

"We let the community decide on the way forward on conservation and development matters during the meetings. For example, in the year 2019, the community identified six sites of Opuntia eradication in in the conservancy. Those are the areas we are working on now"

And that;

"We hold community forum to discuss conservation and the alternative livelihood projects matters. In

the conservancy organization structure, the community comes at the top even before the board. We are just their representatives."

The design of the CBC project broke away from conventional approach of top-down solutions and instead incorporated a bottom-up approach, in the process enabling a more sustainable conservation and development solutions. This is an indication a committed stakeholder engagement and the pivotal position that the design of the $\mathrm{CBC}$ projects has placed the local community in.

The document analysis corroborated these findings by pointing to the local community as being the main decision maker in the conservation projects and management affairs. The document review further shows recognition of equality, inclusivity and diversity, pointing out that elders, women and youth all had a say in the 
management of the conservancy and the alternative livelihood projects that are meant to reduce community reliance on natural resources. Nganga and Robinson (2018) in an International Livestock Research Institute (ILRI) Report on Il Ngwesi Conservancy argued that the local community was actively involved at all stages of livelihood projects and that monitoring and evaluation was done by community members through village forums. The Naibunga and Lekurruki Conservancy Management and Community Development Plans point to decision making on spending priorities to be made at Annual General Meetings with all conservancy members present. Based on the theory of change, the inclusion of local community leads better decisions which in turn meets the needs of the local community therefore improving quality of life.

Further, in the analysis of qualitative strand, there was concurrence that local community values were integrated in the $\mathrm{CBC}$ project design to spur project performance. This was an indication that local culture provided opportunities that reinforced the external expertise on conservation and development initiatives. For instance, community members were engaged in boards and grazing committees where scientific information was combined with traditional knowledge to manage wet and dry season grazing and maintaining grass-banks for extreme drought conditions. Traditional economic practices like cattle grazing, bee keeping (especially in Lekurruki conservancy) and bead works were encouraged. A conservancy chairman added that;

"Our affairs are managed according to our local traditions. The western conservation and development ideas brought by donors and experts are just meant to complement our traditional and indigenous systems."

This cultural orientation of the $\mathrm{CBC}$ projects enhances equity, efficacy and acceptability, which are important thresholds of performance. At this point, it could be confidently stated that integration of local values design aspect is the opposite of fines and fences approach where conservation was expressed in largely incomprehensible scientific and economic terms that lacked local resonance.

From the reviewed documents, the framework-based approach yielded themes that pointed to the fact that traditional community governance was recognized for its potential contributions to understanding biological phenomena, the practice of protecting species and ecosystems and ideas that contributed to the alternative livelihood initiatives. The document analysis showed that science and technology was used in the CBC projects to enrich traditional knowledge systems. For instance, NRT (2018) reports that there is widespread acclamation that traditional grazing systems in use in the conservancies and on the alternative livelihood end, bead work was an economic activity that turns traditional craft into sustainable business. Integration of local values in CBC projects is important since it links conservation and development efforts to the local environmental and cultural context

On the participation of individuals and community groups affected by or interested in a conservation and development, the qualitative stand composed of focused group discussion and the document analysis shed more information that triangulated the survey results. The respondents elucidated that conservation and the local alternative livelihood projects were collectively decided by the community. This was clear from statements like;

"As the chairman of the conservancy board, I don't work alone or with a few selected members, my work it to coordinate conservation and alternative livelihood activities and all members of the community have a say. The conservancy manager under the guidance of our donors implements what the community decides."

A conservancy manager said;

"We hold many meetings with the community members and as managers, we let the community decide the way forward during meetings, we support their full participation and we are not allowed to force ideas on them."

This illumination on the participatory role of the community by the respondents was attested by fact that the conservancies had finance, tourism, grazing and women committees which took the center stage in planning and monitoring conservation and development activities. The respondents also pointed to other community forums that are convened to discuss conservation and alternative livelihood initiatives. These participatory avenues point to a well-entrenched bottom-up approach in management of $\mathrm{CBC}$ projects in the conservancies.

In addition, the document analysis done for triangulation corroborated these findings. The annual reports, conservancy reports and the strategic plans pointed to a participatory planning and management of resource that involved all community members. KWCA (2016) points out that the local communities in conservancy areas were involved in planning, management and resource use. From NRT (2018), expenditure decisions on the alternative livelihood projects were endorsed by community members to reflect local priorities. The NRT (2019) report points to the presence of a participatory approach to monitoring and evaluation which is implemented through village committees/groups. Moreover, Lekurruki Conservancy Management and Community Development Plan 2016-2020 stresses on participatory planning process involving all members of the conservancy. The donors' representative, the NRT reported that participation from conservancy members was generally higher in 2018 compared to previous years (NRT, 2018). In addition, NRT (2019) reported that a number of conservancy boards had incorporated local morans in their teams to increase engagement from this 
demographic. This participation of the local stakeholder in $\mathrm{CBC}$ project planning, implementation and monitoring improves the project design by the use of local community's knowledge; which increases acceptability; yielding a more equitable distribution of benefits; promoting local resource mobilization; and help ensure project sustainability.

\subsection{Comparison of Stakeholder Engagement between the Conservancies}

It was prudent to test whether stakeholder engagement in $\mathrm{CBC}$ projects was similar in all the sampled conservancies. To establish this, a one-way between-groups ANOVA (Welch's t-test) was conducted. Respondents were divided into seven groups according to their conservancies. To carry out the comparison of means, the hypotheses for the test were the following:

$\boldsymbol{H}_{\text {o: }}$ Group means are identical $(\mu A=\mu B)$

$\boldsymbol{H}_{1}:$ Group means are different $(\mu A \neq \mu B)$

Table 2 shows the results of the ANOVA

Table 2: ANOVA Comparisons of Stakeholder Engagement in the Conservancies

\begin{tabular}{|c|c|c|c|c|c|}
\hline \multicolumn{6}{|c|}{ Stakeholder Engagement } \\
\hline & Sum of Squares & df & Mean Square & $\mathbf{F}$ & Sig. \\
\hline Between Groups & 12.315 & 6 & 2.053 & 17.491 & .000 \\
\hline Within Groups & 27.107 & 231 & .117 & & \\
\hline Total & 39.422 & 237 & & & \\
\hline \multicolumn{2}{|c|}{ Robust Tests of Equality of Means } & \multicolumn{3}{|c|}{$\begin{array}{l}\text { Welch Statistic }=19.944 \\
\text { df1 }=6, \text { df } 2=75.765 ; p=.001<0.05\end{array}$} & \\
\hline
\end{tabular}

An examination of the ANOVA Table 2 shows that the group means were different. The differences were statistically significant between the means of the groups as determined by one-way ANOVA, F= 17.491 df $(6,231)$, at $\mathrm{p}=.001$. The results of the Welch two-samples t-test also showed that there was statistically significant difference between the group means, $\mathrm{t}=19.944 \mathrm{df}(6.75 .765), \mathrm{p}=.001<.05$. The null hypothesis $\left(\mathbf{H}_{0}\right)$ was therefore rejected and it was concluded that groups were different. This was an indication that the factoring of stakeholder engagement aspect in the $\mathrm{CBC}$ projects was not the same in all the sampled community conservancies. This confirms that stakeholder engagement is dynamic given that both stakeholders and their interests have temporal and spatial fluidity. The means for groups in homogeneous subsets are displayed in Figure 1.

Figure 1 shows that four homogenous mean subsets emerged. Lekurruki $(\mu=4.0294)$ emerged as the conservancy that factored stakeholder engagement in the project design the most and engaged stakeholders in the $\mathrm{CBC}$ projects to great extent (values between 3.4<GE $>4.2)$. Naibunga Upper $(\mu=3.6886)$, Il Ngwesi $(\mu=$ 3.6238) and Makurian $(\mu=3.5917)$ conservancies were in the second rated homogenous subset in the inclusion of stakeholder engagement in the $\mathrm{CBC}$ project design and too, engaged stakeholders in the CBC projects to great extent (values between 3.4<GE $>4.2$ ). The third homogenous mean subset had Kuri Kuri conservancy $(\mu=$ 3.4078) and Naibunga Lower conservancy $(\mu=3.4000)$, the stakeholder engagement was to a great extent as mean values fell between $3.4<\mathrm{GE}>4.2$. The last subset in terms of stakeholder engagement in $\mathrm{CBC}$ project design was Naibunga Central with a mean $\mu=3.2883$, indication that it was to a moderate extent as mean value fell between $2.6<\mathrm{GE}>3.4$.

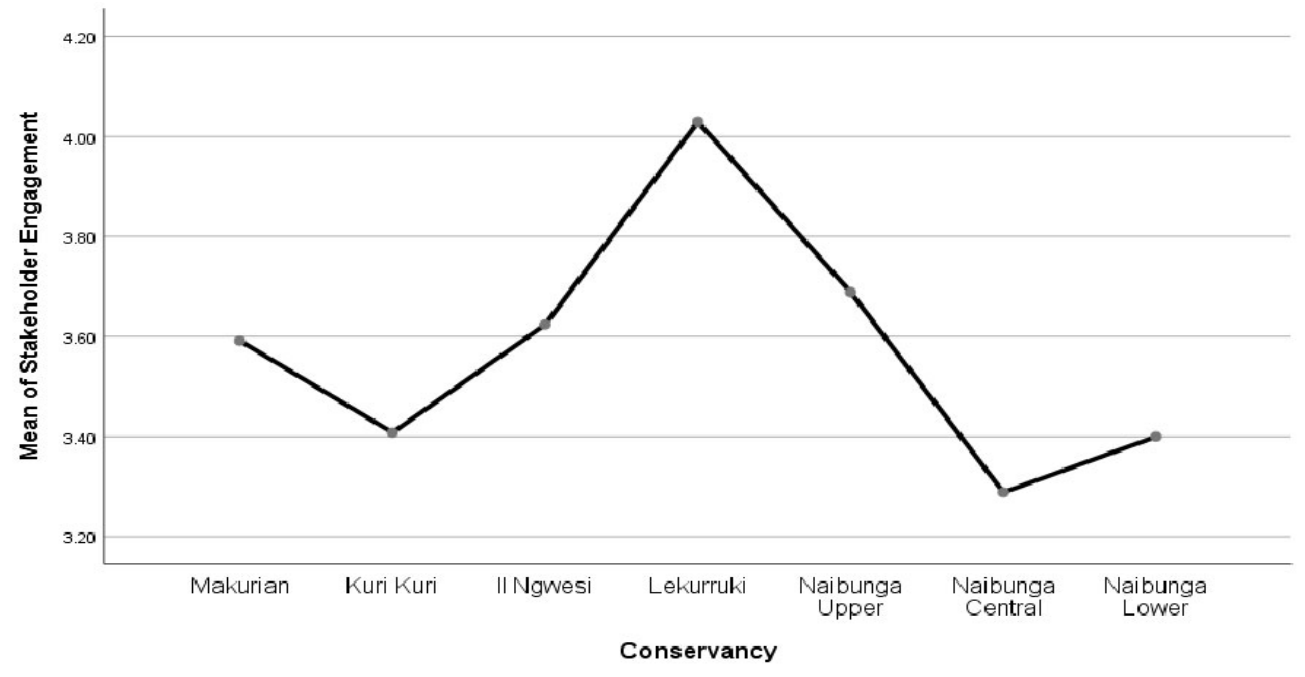

Figure 1: Mean Plot of Stakeholder Engagement in the Conservancies 


\subsection{Relationship between of Stakeholder Engagement and Performance of CBC Projects}

It was an objective of the study to examine the influence of stakeholder engagement on the performance of CBC projects. The Pearson product-moment correlation coefficient was used to measure of the strength and direction of association between of stakeholder engagement and performance of CBC projects. The results are summarized in correlation matrix in Table 3.

According to Table 3, there was a strong and positive relationship $(\mathrm{r}=.641)$ between stakeholder engagement and performance of $\mathrm{CBC}$ projects. Furthermore, the correlation between the two variables is statistically significant at $\mathrm{p}=0.01<0.5$. These results mean that stakeholder engagement was perceived to contribute to performance of $\mathrm{CBC}$ projects in Laikipia region to a great extent.

Table 3: Relationship between Stakeholder Engagement and Performance of CBC Projects

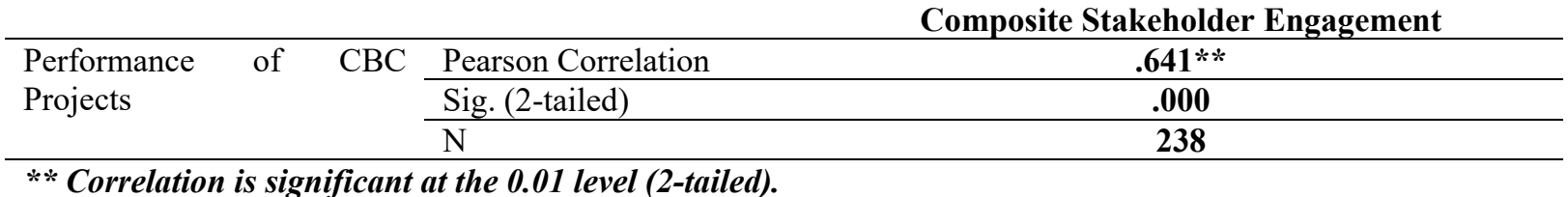

4.4 Test of Hypothesis

Regression analysis was used to assess the plausibility of the study hypothesis using the survey data. The analysis was performed based on the following hypotheses:

$\boldsymbol{H}_{0:}$ There is no significant relationship between stakeholder engagement and performance of CBC projects in Laikipia region.

$\boldsymbol{H}_{1}$ : There is a significant relationship between stakeholder engagement and performance and performance of $C B C$ projects in Laikipia region.

The regression analysis was run to estimate the relationships between a composite index of the dependent variable (performance of $\mathrm{CBC}$ projects) and the composite index of the independent variable (stakeholder engagement). This was to realise a statistical model to predict performance of the CBC projects surveyed in terms of stakeholder engagement. The linear regression model was;

$\mathbf{Y}=\mathbf{a}+\boldsymbol{\beta}_{\mathbf{1}} \mathbf{X}_{\mathrm{ST}}+\mathbf{e}$

Where: $\mathbf{Y}=$ Performance of CBC Projects

$$
\begin{aligned}
& \mathbf{a}=\text { Constant } \\
& \boldsymbol{\beta}_{\mathbf{1}}=\text { Beta coefficient } \\
& \mathbf{X}_{\mathbf{S T}}=\text { Stakeholder Engagement } \\
& \mathbf{e}=\text { error term }
\end{aligned}
$$

\begin{tabular}{|c|c|c|c|c|c|}
\hline Model & $\begin{array}{r}\text { Unst } \\
\mathrm{Ce}\end{array}$ & $\begin{array}{l}\text { rdized } \\
\text { ents }\end{array}$ & $\begin{array}{c}\text { Standardized } \\
\text { Coefficients }\end{array}$ & $\mathbf{t}$ & p-value \\
\hline & $\mathrm{B}$ & Std. Error & Beta & & \\
\hline (Constant) & 1.177 & .202 & & 5.834 & .000 \\
\hline Stakeholder Engagement & .713 & .056 & .641 & 12.813 & .000 \\
\hline \multicolumn{6}{|c|}{$\begin{array}{l}\text { Dependent Variable: Performance of CBC Projects } \\
\text { Predictors: (Constant), Stakeholder Engagement }\end{array}$} \\
\hline $\begin{array}{l}R=.641 \\
R^{2}=.410 \\
F(1,237)=164.169 ; p=.001<.05\end{array}$ & & & & & \\
\hline
\end{tabular}

Table 4 presents summary results of the regression analysis.

Table 4: The Influence of Stakeholder Engagement on Performance of CBC Projects

According to the results in Table $4, \mathrm{r}=0.641$, meaning that stakeholder engagement strongly and positively influenced the performance of $\mathrm{CBC}$ projects. $\mathrm{R}^{2}=0.410$, an illustration that stakeholder engagement could explain 41.0 percent variation in performance of $\mathrm{CBC}$ projects, meaning that, 59.0 percent of variation in the performance of $\mathrm{CBC}$ projects was due to other factors outside the model. The beta value of 0.713 was an indication that a unit increase in stakeholder engagement contributes to 71.3 percent increase in performance of CBC projects. Further, the model is statistically significant at $\mathrm{p}=0.001<0.05$.

The $F$ ratio was statistically significant since $F(1,237)=164.169, p=0.001<0.05$ entailing that there is a statistically significant influence of stakeholder engagement on performance of CBC projects. This therefore provides enough evidence to reject the null hypothesis $\left.\mathbf{( H}_{\mathbf{0}}\right)$ and hence conclude that there is a significant relationship between stakeholder engagement and performance of $\mathrm{CBC}$ projects in Laikipia region at 0.05 level of significance. The results reveal that the extent to which stakeholder engagement is done in the design of CBC projects could to a significant extent determine the performance of the projects.

Using the statistical findings, the regression model can be substituted as follows; 
$\mathrm{Y}=1.177+0.713_{\mathrm{ST}}+0.202$

Where: $\mathrm{Y}=$ Performance of $\mathrm{CBC}$ Projects

\section{$\mathrm{ST}=$ Stakeholder Engagement}

Literature pointed out that stakeholder engagement can range from passive model where stakeholders receive communication about an initiative to full collaborative partnership models. This study established that that public participation as an indicator of local stakeholder engagement was factored in the CBC project design to a great extent $(\mu=3.5049)$. This level of stakeholder engagement through participation is reminiscent with the highest order of engagement. The study found that based on local needs, stakeholder groups were formed and engaged alongside existing ones. These findings comport Type III classification by FAO (2003) in that the highest form of stakeholder engagement involved objective to help create new or strengthen existing self-formed and self-run groups and organizations through which the local communities gain access to resources, inputs and services and participate actively in the project, also by means of self-proposed actions. The results from the qualitative strand further confirmed that the CBOs in the conservancies were self-governed and planned all aspects of conservation and alternative livelihood projects and that external expertise only complemented local efforts. Further, the study agrees with Michener (1998) in that the engagement was people-centred, focusing on improving local communities' self-reliance, social justice, and participatory decision-making. These efforts resonate with community empowerment, an important indicator of $\mathrm{CBC}$ project performance.

The results show that local stakeholder participation was the means and community empowerment was the ends achieved by the $\mathrm{CBC}$ projects. The participation in $\mathrm{CBC}$ projects led conservancy members to assume the control of decisions that affected their lives. The findings of this study are in concurrence with Reeds (2008) that that genuine, people centred, active or transformative participation often leads to empowerment. These stakeholder engagement models increased ownership by stakeholders since the CBC projects valued their views and motivated ultimately leading to sustainability. Moreover, these results are in agreement with Aga et al. (2018) that involving project beneficiaries' project implementation had a significant positive influence on the behavioural intentions of the project beneficiaries toward project sustainability. Participation of community members is important not only for empowerment, but also positively changing attitudinal change towards acceptance of conservation. By participating in the decisions on resource use, the behavioural change towards sustainable resource use was also achieved as very few will act against what they participated in planning.

Integration of local values in the project design was to a great extent $(\mu=3.7668)$. This study has shown that project performance could be enhanced by engaging the local community and their institutions early in the project design stages where indigenous institutions could be utilized in community mobilization and whipping. The results of the study concur with Cebrian-Piqueras et al. (2020) who used multi-variate analysis to show that traditional ecological knowledge was a core principle in conservation project design since it led to improved ecosystem service provision and landscape vulnerability, sustainability as well as resilience of social-ecological systems. These findings are also in agreement with those of Bene and Neiland (2006) who rooted for local engagement through indigenous knowledge and local labour. In addition, the utilization of local knowledge in the project design espouses shared ownership. This concurs with Olukotun (2008) and Hart et al. (2005) shared ownership of the project and the outputs or products of this process by all parties directly involved is of paramount importance for project performance. When project integrates local values, used traditional knowledge systems in its implementation, this brings shared ownership, leading to both attitudinal and behavioural changes to towards the project and its cause, in this case, conservation and rural development.

A major undoing of $\mathrm{CBC}$ project design has been wrong underlying assumptions on the priorities of the local community. The study found that to a great extent, the projects are based on local livelihood priorities ( $\mu=$ 3.47). These findings are in agreement with those of Eskerod et al. (2015) in that understanding and incorporating the needs and concerns of stakeholders is a pathway that an organization can use to design projects that the latter can support and guarantee performance and sustainability of a project. $\mathrm{CBC}$ projects should be designed to channel resources for conservation and local development based on strategic local priorities and thus contribute to a more impactful implementation of local strategies. The CBC project design followed local priority setting where conservation and development priorities specific to the local community were identified and with the help of external expertise, action plans informed by community and conservation needs were developed.

The results showed that inclusion of local stakeholders in CBC project design was to a great extent $(\mu=$ 3.5824). The involvement of local stakeholders in the design stage leads to a higher likelihood of a more effective $\mathrm{CBC}$ project design. The study found that local community was involved in assessment of needs early in the project conception stage $(\mu=3.66)$. Stakeholders should be engaged in the project initiation phase in order to guarantee their own needs and interests. The findings comport those of Bouamrane et al. (2016) that early stakeholder engagement in conservation projects was important in building knowledge for achieving sustainable development. These findings further agree with the view Muhumuza and Balkwill (2013) that stakeholder inclusiveness in conservation projects increased likelihood of more engaged and satisfied stakeholders. Further, 
the results are in agreement with Eskerod et al. (2015) that inclusion removes the danger of loss of focus on those stakeholders with critical resources for the project's survival and progress. Stakeholder inclusion in CBC project design improves the scope as it presents a chance to the community to prioritize local issues in turn leading to acceptance and empowerment.

Overall, local stakeholder engagement was factored in the CBC project design to a great extent $(\mu=3.6006)$. The results are in line with the Stakeholder Theory (Freeman, 1984) as local stakeholders were found to be considered as important in the context of project management. The findings are also in accordance with the theory of participatory development as the $\mathrm{CBC}$ project design allowed actively involving local stakeholders in making decisions about implementation of livelihood and conservation projects that affected them. The findings agree with Heravi et al. (2015) in that engagement at various levels of stakeholder groups established a basis for project success. Effective stakeholder engagement in $\mathrm{CBC}$ projects builds relationships and local community trust essential to realise sustainability. Leveraging expertise from the local community creates strategic, valuedriven, and impactful change.

\subsection{Conclusions and Recommendations}

The study was cognizant that key stakeholder sentiments and insights are valuable, especially in the early stages of project design and planning. An examination of how stakeholder engagement influenced performance of CBC projects was based on the extent of local stakeholders' inclusion, local values integration and participation of locals in the $\mathrm{CBC}$ projects. The study concluded that stakeholder engagement has a significant positive influence on the performance of $\mathrm{CBC}$ projects. In this regard, the improvement of customary use and the traditional knowledge, innovations and practices of indigenous and local communities relevant for the conservation and sustainable use of biodiversity is encouraged.

Being implemented in local community areas, it is prudent that $\mathrm{CBC}$ projects engage with and support indigenous and local communities and local landowners in activities to conserve wildlife and habitats, reduce illegal and unplanned land use. Pursuant to this, external expertise should only be used as a compliment to the local one, therefore use of customary and the traditional knowledge should be improved in the conservancies. This means that innovations and practices of local communities relevant for the conservation and sustainable use of biodiversity ought to be encouraged. Given the importance attached to local knowledge in CBC projects, there is need to have effective communication and outreach to and with local stakeholders, particularly the local cultural institutions who retain traditional ecological knowledge. Such communication and outreach could be best achieved if the design of the project involves engagement not only at the planning stage, but also throughout the project.

\section{References}

Aga, D.A., Noorderhaven, N. \& Vallejo, B. (2018). Project Beneficiary Participation and Behavioral Intentions Promoting Project Sustainability: The Mediating Role of Psychological Ownership, Development Policy Review, 1-20. Retrieved from - wileyonlinelibrary.com/journal/dpr

Bal, M., Bryde, D., Fearon, D. \& Ochieng, E. (2013). Stakeholder Engagement: Achieving Sustainability in the Construction Sector, Sustainability, 5(2), 695-710.

Ballet, J., Koffi, K. \& Komena, K. (2009). Co-Management of Natural Resources in Developing Countries: The Importance of Context, Economie internationale, 120(4), 53-76.

Bene, C. \& Neiland, A.E. (2006). From Participation to Governance: A Critical Review of the Concepts of Governance, Co-Management and Participation and Their Implementation in Small-Scale Inland Fisheries in Developing Countries, World Fish Center Studies and Reviews 2.

Bouamrane, M., Spierenburg, M., Agrawal, A., Boureima, A., Cormier-Salem, M., Etienne, M. et al. (2016). Stakeholder Engagement and Biodiversity Conservation Challenges in Social-Ecological Systems: Some Insights from Biosphere Reserves in Western Africa and France, Ecology and Society 21(4):25.

Brooks, J., Waylen, K.A. \& Mulder, M.B. (2012). How National Context, Project Design, and Local Community Characteristics Influence Success in CBC Projects, Proceedings of the National Academy of Sciences 109(52).

Brooks, J., Waylen, K.A. \& Mulder, M.B. (2013). Assessing CBC Projects: A Systematic Review and Multilevel Analysis of Attitudinal, Behavioral, Ecological and Economic Outcomes, Env. Evid. 2(2).

Brown, M. \& Wyckoff-Baird, B. (1995). Designing Integrated Conservation and Development Projects, WWFUS Biodiversity Support Program, Washington, DC.

Campbell, L.M. \& Vainio-Mattila, A. (2003). Participatory Development and Community-Based Conservation: Opportunities Missed for Lessons Learned? Human Ecology, 31(3), 417-437.

Catacutan, D. C. \& Tanui, J. K. (2007). Engaging Stakeholders in Integrated NRM: Approaches and Guidelines from Land Care, World Agroforestry Centre, www.worldagroforestry.org/.

Cebrian-Piqueras, M., Filyushkina, A., Johnson, D., Lo, V., Rodriguez, M. D., \& March, H. et al. (2020). 
Scientific and Local Ecological Knowledge, Shaping Perceptions Towards Protected Areas and Related Ecosystem Services, Landscape Ecology (35). 10.1007/s10980-020-01107-4.

Cohen, J.M. \& Uphoff, N.T. (1977). Rural Development Participation: Concepts and Measures for Project Design, Implementation and Evaluation, Cornell University, Center for International Studies. Ithaca, New York.

Creswell, J. W., \& Plano Clark, V. L. (2011). Designing and Conducting Mixed Methods Research (2 ${ }^{\text {nd }}$ Ed.). Thousand Oaks, CA: Sage.

Dangi, T.B. \& Jamal, T. (2016). An Integrated Approach to "Sustainable Community-Based Tourism", Sustainability, 8(475), doi:10.3390/su8050475.

Eskerod, P. \& Larsen, T. (2018). Advancing Project Stakeholder Analysis by The Concept 'Shadows of The Context, International Journal of Project Management, 36(1), 161-169.

Eskerod, P., Huemann, M. \& Ringhofer, C. (2015). Stakeholder Inclusiveness: Enriching Project Management with General Stakeholder Theory. PM Journal, 46, 42-53.

FAO (2003). Participatory Development: Guidelines on Beneficiary Participation in Agricultural and Rural Development, Rural Development Division, FAO Rome Italy.

Hart, T., Burgess, R. \& Hart, C. (2005). A Participatory Project Management Cycle: Can It Add Value to Agricultural Development? South African Journal of Agriculture and Extension, 34(2), 201-220.

Heravi, A, Coffey, V. \& Trigunarsyah, B. (2015). Evaluating the Level of Stakeholder Involvement During the Project Planning Processes of Building Projects, International Journal of Project Management, 33(5), 985997.

Krejcie, R. V. and Morgan, D. W. (1970). Determining Sample Size for Research Activities. Educational and Psychological Measurement, 30, 607-610.

KWCA (2016). State of Wildlife Conservancies in Kenya Report, Retrieved from https://kwcakenya.com/download/state-of-wildlife-conservancies-in-kenya-report/

Lantz, B. (2013). Equidistance of Likert-Type Scales and Validation of Inferential Methods Using Experiments and Simulations. Electronic Journal of Business Research Methods (11). 16-28.

Lester, A. (2013). Project Management, Planning and Control: Managing Engineering, Construction and Manufacturing Projects to PMI, APM and BSI Standards: $6^{\text {th }}, 1-567$.

Michener, V.J. (1998). The Participatory Approach: Contradiction and Co-option in Burkina Faso, World Development, 26(12), 2105-2118.

Muhumuza, M. \& Balkwill, K. (2013). Factors Affecting the Success of Conserving Biodiversity in National Parks: A Review of Case Studies from Africa, International Journal of Biodiversity, 1, 1-20.

Nganga, I. and Robinson, L.W (2018). Community-based rangeland management in Il'Ngwesi group ranch, Laikipia, Kenya: Taking successes in land restoration to scale project. ILRI Project Report. Nairobi, Kenya.

NRT (2018). NRT State of Wildlife Conservancies in Kenya Report, Retrieved from https://www.nrtkenya.org/document-library.

NRT (2019). NRT State of Wildlife Conservancies in Kenya Report, Retrieved from https://www.nrtkenya.org/document-library

PMI (2017). A Guide to the Project Management Body of Knowledge (6 ${ }^{\text {th }}$ Ed.), Project Management Institute, Newtown Square, Pennsylvania.

Reed, M.S. (2008). Stakeholder Participation for Environmental Management: A Literature Review, Biological Conservation, 141, $2417-2431$.

Sterling, E.J., Betley, E. Sigouin, A., Gomez, A., Toomey, A., Cullman, G. et al. (2017). Assessing the Evidence for Stakeholder Engagement in Biodiversity Conservation, Biological Conservation, 209, 159-171.

Suich, H. (2013). Evaluating the Household Level Outcomes of Community Based Natural Resource Management: The Tchuma Tchato Project and Kwandu Conservancy. Ecology and Society 18(4), doi.org/10.5751/ES-05875-180425.

Sundaresan, S. R. \& Riginos, C. (2010). Lessons Learned from Biodiversity Conservation in The Private Lands of Laikipia, Kenya, Great Plains Research: A Journal of Natural and Social Sciences, 20 (Spring), 17-27.

Treves, A., Wallace, R. B., Naughton-Treves, L. \& Morales A. (2006). Co-Managing Human-Wildlife Conflicts: A Review, Human Dimensions of Wildlife 1, 1-14.

UNDP (2009). Handbook on Planning, Monitoring and Evaluating for Development Results, United Nations Development Program, New York.

Vargas, A. \& David, F. (2014). Community-Based Conservation Programs and Local People Willingness to Pay for Wildlife Protection: The Case of the Cotton-Top Tamarin in the Colombian Caribbean. Lecturas de Economía. (81). 187. 10.17533/udea.le.n81a7.

Watson, Jeff (2001). How to Determine a Sample Size: Tipsheet \#60, University Park, PA: Retrieved from http://www.extension.psu.edu/evaluation/pdf/TS60.pdf

WCED (1987). Our Common Future, Oxford University Press, London. 